\title{
$1 \quad$ Potassium Chloride-Bearing Ice VII and Ice Planet Dynamics
}

3 Mark R. Frank $^{1^{*}}$, Henry P. Scott ${ }^{2}$, Elizabeth Aarestad ${ }^{1}$, and Vitali B. Prakapenka ${ }^{3}$

4

$5{ }^{1}$ - Department of Geology and Environmental Geosciences, Northern Illinois University,

6 DeKalb, IL 60115 (815-753-8395; mfrank@niu.edu)

7

$8 \quad{ }^{2}$ - Department of Physics and Astronomy, Indiana University South Bend, South Bend,

$9 \quad$ IN 46634

10

$13^{3}$ - Center for Advanced Radiation Sources, University of Chicago, Chicago, IL 60637

12

13

$14 *$ Author to whom correspondence should be addressed (mfrank@ niu.edu).

15

16 Submitted to Geochimica et Cosmochimica Acta

17

18

19

20

21

22

23 


\section{ABSTRACT}

25 Accurate modeling of planetary interiors requires that the pressure-volume-temperature

$26(P V T)$ properties of phases present within the body be well understood. The high-

27 pressure polymorphs of $\mathrm{H}_{2} \mathrm{O}$ have been studied extensively due to the abundance of ice

28 phases in icy moons and, likely, vast number of extra-solar planetary bodies, with only

29 select studies evaluating impurity-laden ices. In this study, ice formed from a 1.6 mole

30 percent $\mathrm{KCl}$-bearing aqueous solution was studied up to $32.89 \pm 0.19 \mathrm{GPa}$ and $625 \mathrm{~K}$, and

31 the incorporation of $\mathrm{K}^{+}$and $\mathrm{Cl}^{-}$ionic impurities into the ice VII structure was

32 documented. The compression data at $295 \mathrm{~K}$ were fit with a third order Birch-

33 Murnaghan equation of state and yielded a bulk modulus $\left(K_{T 0}\right)$, its pressure derivative

$34\left(K_{T 0}^{\prime}\right)$, and zero pressure volume $\left(\mathrm{V}_{0}\right)$ of $24.7 \pm 0.9 \mathrm{GPa}, 4.44 \pm 0.09$, and $39.2 \pm 0.2 \AA^{3}$,

35 respectively. The impurity-laden ice was found to be 6-8\% denser than ice VII formed

36 from pure $\mathrm{H}_{2} \mathrm{O}$. Thermal expansion coefficients were also determined for several

37 isothermal compression curves at elevated temperatures, and a PVT equation of state was

38 obtained. The melting curve of ice VII with incorporated $\mathrm{K}^{+}$and $\mathrm{Cl}^{-}$was estimated by

39 fitting experimental data up to $10.2 \pm 0.4 \mathrm{GPa}$, where melting occurred at $625 \mathrm{~K}$, to the

40 Simon-Glatzel equation. The melting curve of this impurity-laden ice is systematically

41 depressed relative to that of pure $\mathrm{H}_{2} \mathrm{O}$ by approximately $45 \mathrm{~K}$ and $80 \mathrm{~K}$ at 4 and $11 \mathrm{GPa}$,

42 respectively. A portion of the $\mathrm{K}^{+}$and $\mathrm{Cl}^{-}$contained within the ice VII structure was

43 observed to exsolve with increasing temperature. This suggests that an internal

44 differentiating process could concentrate a K-rich phase deep within $\mathrm{H}_{2} \mathrm{O}$-rich planets,

45 and we speculate that this could supply an additional source of heat through the

46 radioactive decay of ${ }^{40} \mathrm{~K}$. Our data illustrate ice VII can incorporate significant 
47 concentrations of $\mathrm{K}^{+}$and $\mathrm{Cl}^{-}$and increasing the possibility of deep-sourced and solute-

48 rich plumes in moderate to large sized $\mathrm{H}_{2} \mathrm{O}$-rich planetary bodies.

\section{INTRODUCTION}

51 The abundance of volatile elements in the universe resulted in a large number of ice-

52 rich planetary bodies clustering in the outer portions of any given solar system due to the

53 low temperatures required for the condensation of ices, such as $\mathrm{H}_{2} \mathrm{O}, \mathrm{CO}_{2}, \mathrm{CO}$, etc

54 (Anderson et al., 1996; Kivelson et al., 1996; Schubert et al., 1996; Anderson et al., 1997;

55 Anderson et al., 1998; Khurana et al., 1998; McCord et al., 1998; Greeley et al., 2000;

56 Anderson et al., 2001; McCord et al., 2001; McCord et al., 2002; Head et al., 2002;

57 Butler et al., 2004; Kuskov and Kronrod, 2005; Gillon et al., 2007). $\mathrm{H}_{2} \mathrm{O}$ is an important

58 component in these domains with it dominating the outer layer of ice in many planetary

59 bodies and taking on different structural configurations within those bodies with ice VI,

60 VII and X being the relevant high-pressure polymorphs (e.g., Hemley et al., 1987; Pruzan

61 et al., 1997; Fortes, A.D. and Choukroun, M., 2010; Men et al., 2014). The presence of

62 active geysers or emanations of $\mathrm{H}_{2} \mathrm{O}$, salts, and other compounds on Europa (Roth et al.,

63 2014), Callisto (Lebofsky, 1977), Ganymede (Saur et al., 2015), and Enceladus (Hansen

64 et al., 2006; Waite et al., 2006; Hsu et al., 2015) suggest subsurface oceans rich in

65 dissolved solutes exist below the outer ice layers (Kargel, 1991; Kargel et al., 1991;

66 Khurana et al., 1998; Kivelson et al., 2000; Zimmer et al., 2000; Ruiz, 2001; Baland and

67 Van Hooist, 2010; Fortes, 2012). The subsurface oceans on these moons are thought to

68 exist between the surface ice, ice Ih, and a higher-pressure form of ice, likely ice V or VI,

69 at depth. Although ice VII is not thought to exist within many of the moons of our solar 
70 system, as it is only stable at pressures greater than $\sim 2 \mathrm{GPa}$, the processes observed on

71 smaller planetary bodies, such as Enceladus and Ganymede, are also likely on larger

$72 \mathrm{H}_{2} \mathrm{O}$-rich planets which have maintained a greater proportion of accretionary heat. This

73 raises questions as to if the deep ices at the base of the subsurface oceans, ice VI in small

74 to moderate sized bodies and ice VII in moderate to large bodies, have formed in contact

75 with the same impurities observed at the surface through interactions with either the

76 subsurface ocean or the deeper rock layers (Hsu et al., 2015). These solutes are well

77 known to affect the density and freezing point of liquid $\mathrm{H}_{2} \mathrm{O}$, but their impacts on solid

$78 \mathrm{H}_{2} \mathrm{O}$-ice are not well constrained. Numerous studies have explored the pure $\mathrm{H}_{2} \mathrm{O}$-ice

79 system (Hemley et al., 1987; Wolanin et al., 1997; Loubeyre et al., 1999; Frank et al.,

80 2004, Fortes et al., 2011; Asahara et al., 2010; Ahart et al., 2011; Hirai et al., 2014), but

81 only a few studies have been conducted in binary $\mathrm{H}_{2} \mathrm{O}$-rich systems. Frank et al. (2006)

82 hypothesized that ice VII could hold ionic impurities and tested the hypothesis in the

$83 \mathrm{NaCl}-\mathrm{H}_{2} \mathrm{O}$ system. They noted that up to 2.4 mole percent $\mathrm{NaCl}$ could be incorporated

84 into ice $\mathrm{VII}$ as $\mathrm{Na}^{+}$and $\mathrm{Cl}^{-}$which decreased the unit cell volume and increased the

85 density of the ice relative to pure ice VII. Subsequently, numerous studies have verified

86 that impurities, such as $\mathrm{NaCl}$ (Frank et al., 2008; Frank et al., 2012; Journaux et al.,

87 2013), $\mathrm{LiCl}$ (Klotz et al., 2009), and $\mathrm{CH}_{3} \mathrm{OH}$ (Frank et al., 2012) could be incorporated

88 into ice VII. Ice VII formed in the $\mathrm{NaCl}-\mathrm{H}_{2} \mathrm{O}$ system has been shown to be denser than

89 pure ice and has also been noted to lower the melting curve relative to pure ice (Frank et

90 al., 2008; Journaux et al., 2013). This study explored ice VII formed in the $\mathrm{KCl}-\mathrm{H}_{2} \mathrm{O}$

91 system to constrain the phase stability, $P V T$ equation of state, melting curve, and

92 potential heat flow from the ice up to $32.9 \mathrm{GPa}$ at $300 \mathrm{~K}$ and $650 \mathrm{~K}$ at $10.6 \mathrm{GPa}$. The 
93 incorporation of $\mathrm{KCl}$ into ice VII would also add ${ }^{40} \mathrm{~K}$, a long lived radioactive isotope of

94 potassium, and produce radiogenic heat from within ice-rich planets. The implications

95 for potential planetary dynamics are profound as the inclusion of $\mathrm{K}^{+}$and $\mathrm{Cl}^{-}$into ice VII

96 could help to drive exchange between deep ice layers, subsurface oceans, and near-

97 surface ice layers and, perhaps, the tenuous atmosphere of these planetary bodies.

98

\section{EXPERIMENTAL AND ANALYTICAL METHODS}

\section{2.1. Experimental Methods}

101 Ice samples containing $\mathrm{K}^{+}$and $\mathrm{Cl}^{-}$were produced by compressing $\mathrm{KCl}-\mathrm{H}_{2} \mathrm{O}$

102 solutions in a diamond anvil cell (DAC). Aqueous solutions containing $\mathrm{KCl}$ were

103 prepared by dissolving $\mathrm{KCl}$ (assay, anhydrous basis $\geq 99.0 \%$ ) in distilled and deionized

$104 \mathrm{H}_{2} \mathrm{O}$. All solutions contained 1.60 mole percent $\mathrm{KCl}$, and this concentration was chosen

105 because it fell below the estimated maximum solubility of $\mathrm{NaCl}$ in ice VII of

106 approximately 2.4 mole percent (Frank et al., 2006), matched the mole percent of $\mathrm{NaCl}$

107 used in the high-temperature study of ice VII by Frank et al. (2008) and allowed for a

108 direct comparison of the ice VII melting curve and thermal expansion.

109 Room-temperature compression experiments were conducted in symmetric

110 diamond anvil cells (DACs), with the diamond anvils having $350 \mu \mathrm{m}$ culets. Inconel 625

111 gaskets were compressed between the anvils to generate a pre-indented area, and sample

112 chambers of approximately $150 \mu \mathrm{m}$ in diameter were drilled in the center of the

113 indentation using an electric discharge machine (EDM). Three to four gold flakes (purity

$114>99.95 \%$ ) between $5-10 \mu \mathrm{m}$ in diameter, to be used as a pressure indicator, were placed

115 in the sample chamber. A drop of the $\mathrm{KCl}-\mathrm{H}_{2} \mathrm{O}$ solution was added to the sample 
116 chamber and immediately sealed by compressing the anvils together to generate pressures

117 greater than $1 \mathrm{GPa}$. The samples were compressed at increments of approximately 0.5

$118 \mathrm{GPa}$ up to approximately $13 \mathrm{GPa}$ and at increased increments up to $32.89 \pm 0.19 \mathrm{GPa}$.

119 High-temperature and high-pressure runs were conducted by using an externally

120 heated Hydrothermal Diamond Anvil Cell (HDAC; Bassett et al., 1993). The diamond

121 anvils had $350 \mu \mathrm{m}$ culets and were mounted on tungsten carbide seats wrapped with

122 chromel wire. The gasket material was Inconel 625 for runs with target pressures below

$1236 \mathrm{GPa}$ and rhenium for experiments at higher pressures. Gaskets were pre-indented to a

124 thickness of 30-45 $\mu \mathrm{m}$ and sample chambers were compressed and loaded as for the

125 room-temperature experiments described above.

126 For each heating step, samples were first compressed to a target pressure while at

127 room temperature. High-temperatures were reached by passing current through the

128 chromel wires wrapped around the tungsten carbide seats of each diamond. The HDAC

129 is designed with an external casing around the cell so that a reducing atmosphere of

130 argon-hydrogen (1\% hydrogen) would prevent oxidation of the diamonds and heaters

131 during high-temperature operation. Temperatures were monitored with type-K

132 thermocouples placed directly against the surface of each diamond and were kept within

$1332 \mathrm{~K}$ of the set temperature during data collection with an overall uncertainty of less than 5

134 K. Data were collected at 50 degree increments at low temperatures and smaller

135 increments near the expected melting point for a given pressure. The actual pressure upon

136 reaching a desired temperature was determined from in situ X-ray diffraction of the gold

137 flakes, as described below.

\section{2.2. Analytical Method}


140 Advanced Photon Source, Argonne National Laboratory. X-ray radiation with a

141 wavelength of $0.3344 \AA$ was focused on the sample for in situ powder diffraction

142 analysis. The X-ray beam was 14 and $7 \mu \mathrm{m}$ in the horizontal and vertical directions,

143 respectively, and was scanned across the sample chamber to search for all phases present

144 in the chamber and to minimize the effects of ice-grain coarsening. An angle dispersive

145 X-ray diffraction technique with a MAR345 online imaging system was used to

146 maximize accuracy and precision. The sample-to-detector distance, coordinates of the

147 directed beam on the detector, and the angle and tilt of the detector were calibrated with

$148 \mathrm{CeO}_{2}$ positioned in the same location as the DAC samples. Data were analyzed by using

149 the FIT2D software package (Hammersley, 1997).

150 X-ray diffraction lines of the ice sample and pressure calibrant (gold) were

151 obtained as a function of temperature as measured by the thermocouples and with

152 pressure calculated from gold diffraction by using its $P V T$ equation of state. The

153 Anderson et al. (1989) model was used to determine pressure rather than newer models

154 (e.g., Fei et al., 2007) to maintain an internal consistency with earlier studies (Frank et al.,

155 2006; Frank et al., 2008). Exposure times of 5 minutes were used for most runs and

156 multiple replicate patterns were taken with increasing time to demonstrate that a steady

157 state had been reached. Variations in the gold unit-cell volume calculated from the (111),

158 (200), (220), (311), and (222) diffraction lines were used to assess deviatoric stresses in

159 the non-hydrostatic DAC (Meng et al., 1993). The uncertainty in the unit cell parameter

160 for gold, and thus the calculated pressure, was determined by taking the $2 \sigma$ standard

161 deviation from the mean of the lattice parameters for gold determined from each of the 
162 five diffraction lines as the minimum uncertainty. This uncertainty was propagated

163 through the pressure calculation to provide a minimum pressure uncertainty as well.

164 Each of the four diffraction lines for ice VII was used calculate a unit cell parameter and

165 a volume at a given pressure and temperature. The uncertainty in the calculated values is

166 the $2 \sigma$ standard deviation from the mean (table 1). Diffraction patterns were monitored

167 for the presence of crystalline $\mathrm{KCl}$ - sylvite (Campbell and Heinz, 1991; Mashimo et al.,

168 2002). There was little overlap of the $\mathrm{KCl}$ and ice VII diffraction lines as at least two

169 independent lines for $\mathrm{KCl}$ and four for ice $\mathrm{VII}$ could be observed over the entire range of

170 temperatures and pressures studied.

171 Diffraction patterns were stacked as a function of pressure and temperature so that

172 phase changes and melting could be easily discerned. Melting was noted upon the

173 disappearance of ice VII diffraction lines and the presence of diffuse scattering while at

174 elevated pressures. Further, after the confirmation of melting, the samples were cooled

175 until diffraction lines indicative of ice VII reappeared. Large ice VII grains sometimes

176 formed during cooling after the melting point had been reached and were difficult to

177 observe with the powder diffraction method. The stage was rotated to help detect the

178 grains in these cases with a success rate of approximately 50\%. The midpoint in pressure

179 and temperature space between ice present and ice absent points was taken to be the

180 melting point for ice VII.

181

182

3. RESULTS

183 3.1. X-ray diffraction of KCl-bearing Ice VII at 295 K 
185 mole percent $\mathrm{K}^{+}$and $\mathrm{Cl}^{-}$were obtained at room temperature, $295 \mathrm{~K}$, from $2.49 \pm 0.04$ to

$18632.89 \pm 0.19 \mathrm{GPa}$ (table 1). The (110), (200) and (211) diffraction lines for ice VII were

187 observed in the majority of the patterns and were used to calculate a unit cell parameter.

188 Gold diffraction lines could be ascribed to (111), (200), (220), (311), and (222) and were

189 present in all patterns (figure 1). Variations in the calculated unit cell parameter for gold

190 from each diffraction line were small and suggested minimal stress in the sample

191 chamber. Diffraction lines indicative of a solid $\mathrm{KCl}$ phase were not observed in any

192 diffraction pattern at $295 \mathrm{~K}$; notably, the X-ray beam was scanned across the majority of

193 the sample chamber to ensure that all phases present were documented. No visual

194 evidence or X-ray diffraction data indicated any phase other than ice VII was present in

195 the sample chamber at $295 \mathrm{~K}$. These data suggest that $\mathrm{K}^{+}$and $\mathrm{Cl}^{-}$were incorporated into

196 the ice VII structure in a manner similar to that of $\mathrm{Na}^{+}$and $\mathrm{Cl}^{-}$(Frank et al., 2006; 2008;

197 2012; Journaux et al., 2013) and $\mathrm{Li}^{+}$and $\mathrm{Cl}^{-}$(Klotz et al., 2009).

198 Ice samples were compressed from $2.49 \pm 0.04$ to $32.89 \pm 0.19$ at $295 \mathrm{~K}$ (figure 2).

199 The ice VII diffraction lines were monitored for phase changes throughout the

200 compression sequence and no changes were observed as ice VII remained in a body-

201 centered cubic structure. Although others have noted peak splitting and suggested that

202 ice VII becomes tetragonal at pressures above approximately 11-14 GPa (Goncharov et

203 al., 1999; Somayazulu et al., 2008; Hirai et al., 2014), no peak splitting was observed

204 over the entire range of pressure-temperature conditions studied and, thus, ice VII was fit

205 as a cubic phase as has been done in the majority of studies (e.g., Hemley et al., 1987; Fei 
et al., 1993; Frank et al., 2004; Frank et al, 2012; Bezacier et al., 2014). The compression

207 data at $295 \mathrm{~K}$ were fit to a third-order Birch-Murnaghan equation of state $(E O S)$ :

208

$$
P(G P a)=\frac{3}{2} K_{T 0}\left[\left(\frac{V_{0}}{V}\right)^{\frac{7}{3}}-\left(\frac{V_{0}}{V}\right)^{\frac{5}{3}}\right] \times\left[1-\frac{3}{4}\left(4-K_{T 0}^{\prime}\right)\left(\left(\frac{V_{0}}{V}\right)^{\frac{2}{3}}-1\right)\right]
$$

209 where $K_{T 0}, K_{T 0}^{\prime}$ and $\mathrm{V}_{0}$ are the isothermal bulk modulus, its pressure derivative and the

210 volume at zero pressure, respectively (Birch, 1978; table 2). $K_{T 0}, K_{T 0}^{\prime}$ and $\mathrm{V}_{0}$ were found

211 to be $24.7 \pm 0.9 \mathrm{GPa}, 4.44 \pm 0.09$, and $39.2 \pm 0.2 \AA^{3}$, respectively. The data indicate that ice

212 VII formed from a 1.60 mole percent $\mathrm{KCl}$ aqueous solution has a unit cell volume which

213 is depressed systematically relative to ice VII formed from $\mathrm{H}_{2} \mathrm{O}$, but roughly equivalent

214 to ice formed from a 1.6 mole percent $\mathrm{NaCl}$ aqueous solution. Further, the compression

215 data and fit parameters are approximately the same as those noted by Frank et al. (2006)

216 for ice VII doped with the same molar concentration of $\mathrm{Na}^{+}$and $\mathrm{Cl}^{-}$(table 2).

218 3.2. X-ray diffraction of KCl-bearing Ice VII at High-temperatures

219 High-temperature X-ray diffraction data were collected up to $625 \mathrm{~K}$ and

$22012.24 \pm 0.12 \mathrm{GPa}$ (table 1 ). These data were monitored for $\mathrm{d}$-spacing values, phase

221 transformations, and melting at increments of 50 or $25 \mathrm{~K}$, depending on proximity to the

222 expected melting point (figure 3). The observed diffraction lines were used to calculate

223 unit cell parameters for gold (pressure indicator), ice VII, and $\mathrm{KCl}$ (if present). Ice VII

224 was determined to be the only $\mathrm{H}_{2} \mathrm{O}$-rich phase over the entire pressure-temperature range

225 investigated. The lattice parameters and unit cell volume were calculated assuming a

226 body-centered cubic structure. Calculated volumes of ice VII at elevated pressure and

227 temperature were used to determine thermal expansion by using the volume coefficient of 228 thermal expansion, $\alpha(\mathrm{P}, \mathrm{T})$, as defined by: 


$$
\alpha(P . T)=\alpha_{0}(T)\left[1+\left(\frac{K_{T 0}^{\prime}}{K_{T 0}} \times P\right)^{-n}\right]
$$

230 The $\alpha_{0}(\mathrm{~T})$ term is the thermal expansion coefficient at zero pressure and can be

231 expressed as:

$$
\alpha_{0}=a_{0}+a_{1} T
$$

233 where the empirical coefficients $a_{0}$ and $a_{1}$ were determined to be $-2.93 \times 10^{-4}$ and $1.27 \times 10^{-}$

$2346 / K$, respectively. The pressure effect on the measured volume, $\eta$, was calculated to be

235 0.77. The Pressure-Volume-Temperature equation of state model developed here for

$236 \mathrm{KCl}-$ enriched ice VII matched closely the data from the experiments (figure 4) and is

237 compared to those for ice VII formed from pure $\mathrm{H}_{2} \mathrm{O}$ systems (e.g., Fei et al., 1993; Frank

238 et al., 2004) and the $\mathrm{NaCl}-\mathrm{H}_{2} \mathrm{O}$ system (Frank et al., 2008) in table 3.

\section{3.3. Melting Curve of KCl-bearing Ice VII}

The absence of ice VII diffraction lines and the presence of diffuse scattering

242 upon increasing temperature or decreasing pressure at a given temperature were assumed

243 to be the result of ice VII melting. The midpoint between ice-present and ice-absent

244 pressure-temperature data were defined as the melting point with the uncertainty on the

245 midpoint being half the difference in pressure and temperature space between the

246 adjacent data (table 4; figure 5). The estimated melting-point data were fit with a Simon-

247 Glatzel equation (Simon and Glatzel, 1929):

$$
P=\left[P_{c} \times\left\{\left(\frac{T}{T_{t}}\right)^{c}-1\right\}\right]-P_{t}
$$

249 where $\mathrm{P}, \mathrm{P}_{\mathrm{t}}, \mathrm{P}_{\mathrm{C}}, \mathrm{T}, \mathrm{T}_{\mathrm{t}}$, and $\mathrm{c}$ are the pressure along the melting curve, pressure at the ice

250 VII-ice VI-fluid triple point, the pressure best-fit parameter, the temperature along the 
251 melting point, temperature at the triple point, and another best-fit parameter, respectively

252 (table 4). The $\mathrm{P}_{\mathrm{t}}$ and $\mathrm{P}_{\mathrm{c}}$ values used in this study were derived from the melting point

253 data presented here rather than the values established for pure ice VII. The calculated

254 melting curve closely matches the experimental data that were previously determined for

255 ice VII formed from a 1.6 mole percent $\mathrm{NaCl}-\mathrm{H}_{2} \mathrm{O}$ aqueous solution (Frank et al., 2008),

256 except at pressures less than $3 \mathrm{GPa}$ and greater than $12 \mathrm{GPa}$. The melting point of ice VII

257 formed from a 1.60 mole percent $\mathrm{KCl}-\mathrm{H}_{2} \mathrm{O}$ solution is systematically depressed relative

258 to pure ice VII (Lin et al., 2004; Datchi et al., 2000) at all pressures; the observed

259 depression is approximately $45 \mathrm{~K}$ and $80 \mathrm{~K}$ at 4 and $11 \mathrm{GPa}$, respectively.

\section{DISCUSSION}

\section{4.1. Pressure-Volume-Temperature Equation of State}

263 The volume of ice VII formed from a 1.60 mole percent $\mathrm{KCl}-\mathrm{H}_{2} \mathrm{O}$ solution was

264 monitored up to $32.9 \mathrm{GPa}$ at $295 \mathrm{~K}$. The diffraction patterns collected at $295 \mathrm{~K}$ showed

265 no evidence of a solid $\mathrm{KCl}$ phase, which is consistent with previous work and suggests

266 that the ice VII structure can accommodate significant ionic impurities (Frank et al.,

267 2006; Frank et al., 2012; Klotz et al., 2009). Equation of state data from this and earlier

268 studies were used to compare modelled $P$ - $V$ curves for pure ice VII (Hemley et al., 1987;

269 Fei et al., 1993; Frank et al., 2012; Bezacier et al., 2014), ice VII with impurities of $\mathrm{Na}^{+}$

270 and $\mathrm{Cl}^{-}$(Frank et al., 2006; Frank et al., 2012) and now ice VII with impurities of $\mathrm{K}^{+}$and

$271 \mathrm{Cl}^{-}$. The volume of ice VII with included $\mathrm{K}^{+}$and $\mathrm{Cl}^{-}$as a function of pressure at $295 \mathrm{~K}$ is

272 consistent with ice formed with $\mathrm{Na}^{+}$and $\mathrm{Cl}^{-}$, but it is systematically less than that of pure

273 ice VII (figure 2). This suggests that the difference in ionic radii of $\mathrm{Na}^{+}$and $\mathrm{K}^{+}$were less 
274 important than the size of $\mathrm{Cl}^{-}$in controlling the volumetric properties of solute-bearing 275 ice VII.

276 The $K_{T 0}$ and $K_{T 0}^{\prime}$ values for ice VII with included $\mathrm{K}^{+}$and $\mathrm{Cl}^{-}$are broadly consistent

277 with values determined by previous workers in both pure and impurity-rich system (table

2782 for studies that reported a $3^{\text {rd }}$ order Birch-Murnaghan equation of state). The data

279 support the hypothesis of Frank et al. (2006) who suggested that ionic impurities will

280 decrease the volume of ice VII while molecular impurities cause an increase in volume

281 (Frank et al., 2012).

282 Experiments were conducted at elevated temperatures to measure the thermal

283 expansion of the ice samples as well as to determine the melting curve. Samples were

284 heated initially at increments of $50 \mathrm{~K}$ and smaller increments near the estimated melting

285 curve (figure 5). Although efforts were made to heat the sample isobarically, there was

286 often a change in pressure during heating, thus, great care was taken in measuring the

287 diffraction patterns with increasing temperature to constrain pressure variations (figure

288 3). Two diffraction lines indicative of crystalline $\mathrm{KCl}$ were observed to form during the

289 heating cycle in all experimental runs (figure 3 ). This newly observed $\mathrm{KCl}$ is thought to

290 form as a result of exsolution of the $\mathrm{K}^{+}$and $\mathrm{Cl}^{-}$that was contained within the ice VII

291 initially; a similar phenomenon was observed in the $\mathrm{NaCl}-\mathrm{H}_{2} \mathrm{O}$ system (Frank et al.,

292 2008). Frank et al. (2008) hypothesized that such exsolution could be driven by an

293 entropic effect, as increasing temperature would likely decrease the ordering within

294 impurity-laden ice, and thus exsolution to form a separate, but pure, ionic salt phase may 295 be favored thermodynamically. 
The thermal expansion coefficient data are broadly consistent with previous studies

297 on ice VII (Fei et al., 1993, Frank et al., 2004, Frank et al., 2008; and Bezacier et al.,

298 2014) suggesting that an increase in temperature has a similar effect on the volume of

299 both pure and impurity laden ice VII (table 3). The minimal variation in the thermal

300 expansion suggests that the exsolution of $\mathrm{KCl}$ was minor at elevated temperatures as it

301 did not substantially impact the observed volume, although it is difficult to estimate the

302 actual amount of exsolved $\mathrm{KCl}$.

\section{4.2. Melting Curve of Ice $\mathrm{VII}$ formed from a $\mathrm{KCl}-\mathrm{H}_{2} \mathrm{O}$ aqueous solution}

305 The melting of ice VII with incorporated $\mathrm{K}^{+}$and $\mathrm{Cl}^{-}$was determined up to $625 \mathrm{~K}$ and

$306 \quad 10.6 \mathrm{GPa}$ and was fit by using a Simon-Glatzel equation. Melting of the impurity-laden

307 ice occurred at lower temperatures ( $45 \mathrm{~K}$ and $80 \mathrm{~K}$ at 4 and $11 \mathrm{GPa}$, respectively) than

308 pure ice VII (e.g., Lin et al., 2004; Datchi et al., 2000). The depression of the melting

309 curve at any given pressure is due to either the presence of the included $\mathrm{K}^{+}$and $\mathrm{Cl}^{-}$or the

310 solid $\mathrm{KCl}$ that exsolved from the $\mathrm{KCl}$-doped ice (figure 5). Frank et al. (2008)

311 documented the melting curve of ice VII formed from a 1.6 mole percent $\mathrm{NaCl}-\mathrm{H}_{2} \mathrm{O}$

312 aqueous solution. Their melting curve closely matches that observed in this study with a

313 noted deviation at 2.2-3.5 GPa where they had no data and used the triple point of pure

314 ice VII, ice VI and fluid. The data presented here indicate that the melting curve is

315 depressed at these pressures as well which will increase the fluid stability field in

316 pressure-temperature space. This has also been documented by Journaux et al. (2013) for

317 the $\mathrm{NaCl}-\mathrm{H}_{2} \mathrm{O}$ system. These data, when consider in totality, indicate that ionic 
318 impurities, such as $\mathrm{Na}^{+}, \mathrm{K}^{+}$, and $\mathrm{Cl}^{-}$, can be incorporated into ice VII and will lower the

319 melting curve substantially.

\section{IMPLICATIONS}

322 The formation of ice VII from an ionic aqueous solution results in an impurity-laden

323 ice VII phase, and such ionic impurities have been shown to decrease the volume of ice

324 VII at any given pressures (Frank et al., 2006, Frank et al., 2008, Frank et al., 2012; this

325 study). The increase in atomic mass within the unit cell, along with the reduction in unit

326 cell volume, results in a density increase for the KCl-rich ice by approximately $8 \%$ and

$3276 \%$ at 3 and $30 \mathrm{GPa}$, respectively, relative to pure ice VII (figure 6). The calculated

328 density of pure ice from Bezacier et al. (2014), Frank et al. (2012), Frank et al., (2004),

329 Fei et al. (1993) was found to be within 1-2\% of that of Hemley et al. (1987), indicating

330 that while there is variability between every study, the density difference for ice in the

$331 \mathrm{KCl}-\mathrm{H}_{2} \mathrm{O}$ system was much greater than would be expected from only experimental 332 uncertainty.

333 The potassium included within the ice will also provide a source of radiogenic heat as

334 the decay of ${ }^{40} \mathrm{~K}$ contributes $2.7 \mu \mathrm{cal} / \mathrm{g}$.year for each wt.\% of $\mathrm{K}$ (Birch, 1951). The

335 results presented here suggest up to at least $3.33 \mathrm{wt} . \%$ can be incorporated into the

336 structure of ice VII which can provide a notable source of heat. Thus, the ice VII layers

337 of large, extra-solar $\mathrm{H}_{2} \mathrm{O}$-rich planetary bodies may also be a source of radiogenic heat.

338 Ice VII is stable at pressures greater than $2 \mathrm{GPa}$ and is not likely a major phase

339 within the Galilean satellites, with the possible exception of Callisto, however, the

340 surface features observed on those moons and the deeper ice-fluid interactions that 
341 produce those features indicate $\mathrm{H}_{2} \mathrm{O}$-rich planetary bodies that have internal heat sources

342 can be dynamic and may have convective deep ice layers. These data also suggest that

343 ionic impurities in ice VII will increase the vigor of convective motions through ice VII-

344 bearing mantles by increasing the density contrast between pure and impurity laden ice

345 and also by promoting internal melting of ice. The hypothetical extra-solar planet

346 depicted in figure 7 has a geothermal gradient that crosses from low-pressure ice Ih

347 through the fluid phase field and directly into the ice VII stability field. This scenario

348 allows for impurity-laden ice VII to form directly from a fluid which would subduct or

349 sink below pure ice due to its greater density. This hypothetical process could bring

350 impurity-laden ice deep into the planet where temperatures and pressures are elevated.

351 Although the rheology of the solute-bearing ice is not well constrained, ice VI is thought

352 to deform through dislocation creep (Durham et al., 1996), and it seems likely that ice VII

353 may deform similarly. The addition of impurities, and the presence of solid $\mathrm{KCl}$, which

354 can also deform through dislocation and point defects (Kobayashi et al., 1995; Shuldiner

355 and Zakrevskii, 2002) at elevated temperatures should increase the deformation and flow

356 within such ice layers. The greater ductility and lower melting point of $\mathrm{KCl}$-bearing ice

357 VII, relative to pure ice VII, could produce plumes of fluid that rise towards the surface

358 of the planet. The ice-fluid convection could also recycle materials from deep within the

359 body and provide deep-sourced solutes and heat to the subsurface ocean. A large density

360 difference between the rising plume and surrounding material could allow for the plume

361 to broach the deeper ice layers and initiate currents in the subsurface oceans that

362 contribute to surficial geyser-like activity. Geysers have been observed on many $\mathrm{H}_{2} \mathrm{O}$ -

363 rich moons (e.g., Lebofsky, 1977; McCord et al., 2001; McCord et al., 2002; Baland and 
364 Van Hooist, 2010; Roth et al., 2014; Saur et al., 2015) and have been linked to ice

365 “overturn" on Enceladus, Ganymede and other $\mathrm{H}_{2} \mathrm{O}$-rich moons (McKinnon, 1999;

366 O’Neill and Nimmo, 2010) and could possibly lead to surface flooding as observed on

367 Ganymede (Schenk et al., 2001). Therefore, the presence of solutes within ice VII

368 increases the density of the ice, lowers the melting curve relative to pure ice VII,

369 increases the possibility of ice convection, and makes plumes of solute-rich fluids

370 possible.

371

\section{CONCLUSIONS}

373 The phase relations and volumetric properties of high-pressure phases of $\mathrm{H}_{2} \mathrm{O}$ are

374 important in planetary physics as a large number of planets and moons exist at great

375 enough distances from stars to have formed at temperatures below ice condensation

376 temperatures. This study examined ice VII formed in the $\mathrm{KCl}-\mathrm{H}_{2} \mathrm{O}$ system to ascertain if

$377 \mathrm{~K}^{+}$and $\mathrm{Cl}^{-}$could be included into the structure of ice VII and to constrain the volumetric

378 properties and behavior of this impurity-laden ice. 1.6 mole percent of $\mathrm{K}^{+}$and $\mathrm{Cl}^{-}$were

379 incorporated into the structure of ice VII which: 1) increased the density relative to pure

380 ice VII by 6-8\% (compared to the model from Hemley et al., 1987); 2) induced

381 exsolution of a $\mathrm{KCl}$ solid phase from the impurity-laden ice VII with increasing

382 temperature; 3 ) lowered the melting curve by up to $80 \mathrm{~K}$ at $12 \mathrm{GPa}$ relative to pure ice

383 VII; 4) increased the likelihood that the ice layer produced heat through the decay of ${ }^{40} \mathrm{~K}$;

384 5) provides a possible mechanism for ice convection driven by subduction-like processes

385 and deep ice plume generation, and 7) a source of deep material for subsurface oceans

386 and their surface manifestations. 
389 Illinois University (MRF). This research used resources of the Advanced Photon Source,

390 a U.S. Department of Energy (DOE) Office of Science User Facility operated for the

391 DOE Office of Science by Argonne National Laboratory under Contract No. DE-AC02-

392 06CH11357. We acknowledge the support of GeoSoilEnviroCARS (Sector 13), which

393 is supported by the National Science Foundation - Earth Sciences (EAR-1128799), and

394 the Department of Energy, Geosciences (DE-FG02-94ER14466). 
410

411

412

413

414

415

416

417

418

419

420

421

422

423

424

425

426

427

428

429

430

431

432

433

434

435

436

437

438

439

440

441

442

443

444

445

446

447

448

449

450

451

452

453

Ahart, M., Somayazulu, M., Gramsch, S., Boehler, R., Mao, H.K., and Hemley, R.J. (2011) Brillouin scattering of $\mathrm{H}_{2} \mathrm{O}$ ice to megabar pressures. Journal of Chemical Physics, 134, 124517.

Ahart, M., Karandikar, A., Gramsch, S., and Boehler, R. (2014) High P-T Brillouin scattering study of $\mathrm{H}_{2} \mathrm{O}$ melting to $26 \mathrm{GPa}$. High Pressure Research, 34, 327 336.

Anderson, J.D., Jacobson, R.A., McElrath, T.P., Moore, W.B., Schubert, G., and Thomas, P.C. (2001) Shape, mean radius, gravity field, and interior structure of Callisto. Icarus 153, 157-161.

Anderson, J.D., Lau, E.L. Sjogren, W.L. Schubert, G. and Moore, W.B. (1996) Gravitational constraints on the internal structure of Ganymede. Nature 384, 541543.

Anderson, J.D., Lau, E.L. Sjogren, W.L. Schubert, G. and Moore, W.B. (1997) Gravitational evidence for an undifferentiated Callisto. Nature 387, 264-266.

Anderson, J.D., Schubert, G., Jacobson R.A., Lau, E.L., Moore, W.B., and Sjorgren W.L. (1998) Distribution of rock, metals, and ices in Callisto. Science 280, 1573-1576.

Anderson, O.L., Isaak, D.G., and Yamamoto, S. (1989) Anharmonicity and the equation of state for gold. J. Appl. Phys. 65, 1534-1543.

Asahara, Y., Hirose, K., Ohishi, Y., Hirao, N., and Murakami, M. (2010) Thermoelastic properties of ice VII and its high-pressure polymorphs; implications for dynamics of cold slab subduction in the lower mantle. Earth and Planetary Science Letters, 299, 474-482.

Baland, R.M. and Van Hooist, T. (2010) Librations of the Galilean satellites: The influence of global internal liquid layers. Icarus 209, 651-664.

Bassett, W.A., Shen, A.H., Bucknum, M., and Chou, I. M. (1993) Hydrothermal studies in a new diamond anvil cell up to $10 \mathrm{GPa}$ and from -190 to $1200{ }^{\circ} \mathrm{C}$. Pure and Applied Geophysics 141, 487-496.

Bezacier, L., Journaux, B., Perrillat, J-P., Cardon, H., Hanfland, M., and Daniel, I. (2014) Equations of state of ice VI and ice VII at high pressure and high temperature. Journal of Chemical Physics 141, 104505-6.

Birch, F (1951) Recent Work on the radioactivity of potassium and some related geophysical problems. J. Geophys. Res. 56, 107-126.

Birch, F. (1978) Finite strain isotherm and velocities for single-crystal and polycrystalline $\mathrm{NaCl}$ at high pressures and 300 degrees K. J.Geophys. Res. A 83, 1257-1268

Butler, R.P., Vogt, S.S., Marcy, G.W., Fischer, D.A., Wright, J.T., Henry, G.W., Laughlin, G., and Lissauer, J.J. (2004) A Neptune-Mass Planet Orbiting the Nearby M Dwarf GJ 436. Astrophysical Journal 617, 580-588.

Campbell, A.J. and Heinz, D.L. (1991) Compression of KCl in the B2 structure to 56 GPa. Journal of the Physics and Chemistry of Solids 52, 495-499.

Datchi, F., Loubeyre, P. and LeToullec, R. (2000) Extended and accurate determination of the melting curves of argon, helium, ice $\left(\mathrm{H}_{2} \mathrm{O}\right)$, and hydrogen $\left(\mathrm{H}_{2}\right)$. Physical Review B 61, 6535-6546.

Dubrovinskaia, N. and Dubrovinsky, L. (2003) Melting curve of water studied in externally heated diamond-anvil cell. High Pressure Research 23, 307-311. 
Durham, W.B., Stern, L.A. and Kirby, S.H. (1996) Rheology of water ices V and VI. J. Geophysical Res., B, Solid Earth and Planets 101, 2989-3001.

Fei, Y., Mao, H.K. and Hemley, R.J. (1993) Thermal expansivity, bulk modulus, and melting curve of $\mathrm{H}_{2} \mathrm{O}-\mathrm{Ice}$ VII to $20 \mathrm{GPa}$. J. Chem. Phys. 99, 5369-5373.

Fei, Y., Ricolleau, A., Frank, M.R., Mibe, K., Shen, G. and Prakapenka, V. (2007) Pressure Scales at High Temperature: Thermal Equations of State of the NaCl-B2 Phase and Solid Neon. Proc. Natl. Acad. Sci. 10.1073/pnas.0609013104, 104, 9182-9186.

Fortes, A.D. (2012) Titan's internal structure and the evolutionary consequences. Planetary and Space Sciences 60, 10-17.

Fortes, A.D. and Choukroun, M. (2010) Phase Behavior of ices and hydrates. Space Sci. Rev. 153, 185-218.

Fortes, A.D., Wood, I.G., Tucker, M.G., and Marshall, W.G. (2011) The $P-V$-T equation of state of $\mathrm{D}_{2} \mathrm{O}$ ice VI determined by neutron powder diffraction in the range $0<$ $P<2.6 \mathrm{GPa}$ and $120<T<330 \mathrm{~K}$, and the isothermal equation of state of $\mathrm{D}_{2} \mathrm{O}$ ice VII from 2 to $7 \mathrm{GPa}$ at room temperature. Journal of Applied Crystallography $\mathbf{4 5}$, 523-534.

Frank, M.R., Fei, Y., and Hu, J. (2004) Constraining the equation of state of fluid $\mathrm{H}_{2} \mathrm{O}$ to $80 \mathrm{GPa}$ using the melting curve, bulk modulus and thermal expansivity of Ice VII. Geochim. Cosmochim. Acta 68, 13, 2781-2790.

Frank, M.R., Runge, C.E., Scott, H.P., Maglio, S.J., Olson, J., Prakapenka, V.B., and Shen, G. (2006) Experimental Study of the $\mathrm{NaCl}-\mathrm{H}_{2} \mathrm{O}$ System up to $28 \mathrm{GPa}$ : Implications for Ice-rich Planetary Bodies. Physics of the Earth and Planetary Interiors 155, 152-162.

Frank, M.R., Scott, H.P, Maglio, S.J. Prakapenka, V.B., Shen, G. (2008) Temperature induced immiscibility on the $\mathrm{NaCl}-\mathrm{H}_{2} \mathrm{O}$ system at high pressure. Physics of the Earth and Planetary Interiors 170, 107-114.

Frank, M.R., Aarestad, E., Scott, H.P., and Prakapenka, V.B. (2012) A comparison of ice VII formed in the $\mathrm{H}_{2} \mathrm{O}, \mathrm{NaCl}-\mathrm{H}_{2} \mathrm{O}$, and $\mathrm{CH}_{3} \mathrm{OH}-\mathrm{H}_{2} \mathrm{O}$ systems: Implications for $\mathrm{H}_{2} \mathrm{O}$-rich planets. Physics of the Earth and Planetary Interior 215, 12-20.

Gillon, M., Pont F., Demory B.-O., Mallmann, F., Mayor, M., Mazeh, T., Queloz, D., Shporer, A., Udry, S., and Vuissoz, C. (2007) Detection of transits of the nearby hot Neptune GJ 436 b. Astronomy and Astrophysics 472, L13-L16.

Goncharov, A.F., Struzhkin, V.V., Mao, H.K. and Hemley, R.J. (1999) Raman spectroscopy of dense $\mathrm{H}_{2} \mathrm{O}$ and the transition to symmetric hydrogen bonds. Phys. Rev. Lett. 83, 1998-2001.

Greeley, R.; Figueredo, P. H.; Williams, D. A.; Chuang, F. C.; Klemaszewski, J. E.; Kadel, S. D.; Prockter, L. M.; Pappalardo, R. T.; Head, J. W., III; Collins, G. C.; Spaun, N. A.; Sullivan, R. J.; Moore, J. M.; Senske, D. A.; Tufts, B. R.; Johnson, T. V. ; Belton, M. J. S.; and Tanaka, K. L. (2000) Geologic mapping of Europa. Journal of Geophysical Research, E, Planets, 105, 22,559-22,578.

Hammersley, A.P. (1997) FIT2D: An introduction and overview. ESRF Internal Report ESRF97HA02T.

Hansen, C.J., Esposito, L., Stewart, A.I.F., Colwell, J., Hendrix, A., Pryor, W., Shemansky, D., and West, R. (2006) Enceladus' Water Vapor Plume. Science 311, n. 5766, 1422-1425. 
Head, J. W.; Pappalardo, R.; Collins, G.; Belton, M. J. S.; Giese, B.; Wagner, R.; Breneman, H.; Spaun, N.; Nixon, B.; Neukum, G.; Moore, J. (2002) Evidence for Europa-like tectonic resurfacing styles on Ganymede. Geophysical Research Letters 29, 1-4.

Hemley, R.J., Jephcoat, A.P., Mao, H.K., Zha, C.S., Finger, L.W. and Cox, D.E. (1987) Static compression of $\mathrm{H}_{2} \mathrm{O}$-ice to $128 \mathrm{GPa}$ (1.28 Mbar). Nature 330, 737-740.

Hirai, H., Kadobayashi, H., Matsuoka, T., Ohishi, Y., and Yamamoto, Y. (2014) High pressure X-ray diffraction and Raman spectroscopic studies of the phase change of $\mathrm{D}_{2} \mathrm{O}$ ice VII at approximately $11 \mathrm{GPa}$. High Pressure Research 34, 289-296, DOI: 10.1080/08957959.2014.913041.

Hsu, H.W., Postberg, F., Sekine, Y., Shibuya, T., Kempf, S., Horányi, M., Juhász, A., Altobelli, N., Suzuki, K., Masaki, Y., Kuwatani, T., Tachibana, S., Sirono, S., Moragas-Klostermeyer, G., and Srama, R. (2015) Ongoing hydrothermal activities within Enceladus. Nature 519, 207-210.

Journaux, B., Daniel, I., Caracas, R., Montagnac, G., and Cardon, H. (2013) Influence of $\mathrm{NaCl}$ on ice VI and ice VII melting curves up to $6 \mathrm{GPa}$, implications for large icy moons. Icarus 226, 355-363.

Kargel, J.S. (1991) Brine volcanism and the interior structures of asteroids and satellites. Icarus 94, 368-390.

Kargel, J.S., Croft, S.K., Lunine, J.I. and Lewis, J.S. (1991) Rheological properties of ammonia-water liquids and crystal-liquid slurries: Planetological applications. Icarus 89, 93-112.

Khurana, K.K., Kivelson, M.G., Stevenson, D.J., Schubert, G., Russell, C.T., Walker, R.J., and Polansky, C. (1998) Induced magnetic fields as evidence for subsurface oceans in Europa and Callisto. Nature 395, 777-780.

Kivelson, M.G.; Khurana, K.K.; Russell, C.T.; Walker, R.J.; Warnecke, J.; Coroniti, F.V.; Polanskey, C.; Southwood, D. J.; Schubert, G. (1996) Discovery of Ganymede's magnetic field by the Galileo spacecraft. Nature 384, 537-541.

Kivelson, M.G., Khurana, K.K., Russell, C.T., Volwerk, M., Walker, R.J. and Zimmer, C. (2000) Galileo magnetometer measurements: A stronger case for a subsurface ocean at Europa. Science 289, 1340-1343.

Klotz, S. Bove, L., Strassle, T., Hansen, T., Saitta, A. (2009) The preparation and structure of salty ice VII under pressure. Nature Materials 8, 405-409.

Kobayashi, S., Nakata, I., and Miura, S. (1995) Deformation in KCl single crystals with spherical indenter above room temperature. Journal of the Society of Materials Science 44, 1151-1156.

Kuskov, O.L., and Kronrod, V.A. (2001) Core sizes and internal structure of Earth's and Jupiter's satellites. Icarus 151, 204-227.

Kuskov, O.L., and Kronrod, V.A. (2005) Internal structure of Europa and Callisto. Icarus 177, 550-569.

Lebofsky, L.A. (1977) Identification of water frost on Callisto. Nature 269, 785-787.

Lin, J-F., Militzer, B., Struzhkin, V.V., Gregoryanz, E., Hemley, R.J., and Mao, H-k. (2004) High pressure-temperature Raman measurements of $\mathrm{H}_{2} \mathrm{O}$ melting to 22 GPa and 900 K. Journal of Chemical Physics 121, 8423-8427. 
Loubeyre, P., LeToullec, R., Wolanin, E., Hanfland, M. and Häusermann, D. (1999) Modulated phases and proton centering in ice observed by X-ray diffraction up to 170 GPa. Nature 397, 503-506.

Mashimo, T., Nakamura, K., Tsumoto, K., Zhang, Y. Ando, S., and Tonda, H. (2002) Phase transition of $\mathrm{KCl}$ under shock compression. Journal of Physics: Condensed Matter 14, 10783-10785.

McCord, T.B., Hansen, G.B., Fanale, F.P., Carlson, R.W., Matson, D.L., Johnson, T.V., Smythe, W.D., Crowley, J.K., Martin, P.D., Ocampo, A., Hibbitts, C.A. and Granahan, J.C. (1998) Salts on Europa's surface detected by Galileo's near infrared mapping spectrometer. Science 280, 1242-1245.

McCord, T.B., Hansen, G.B. and Hibbitts, C.A. (2001) Hydrated salt minerals on Ganymede's surface: Evidence of an ocean below. Science 292, 1523-1525.

McCord, T.B., Teeter, G., Hansen, G.B., Sieger, M.T., Orlando, T.M. (2002) Brines exposed to Europa surface conditions. Journal of Geophysical Research 107, 1-6.

McKinnon, W. B. (1999) Convective instability in Europa's floating ice shell. Geophys. Res. Lett. 26, 951-954.

Men, Z., Fang, W., Li, D., Li Z., and Sun, C. (2014) Raman spectra from symmetric hydrogen bonds in water by high-intensity laser-induced breakdown. Nature 4, 4606, doi:10.1038/srep04606.

Meng, Y., Weidner, D.J. and Fei., Y. (1993) Deviatoric stress in a quasi-hydrostatic diamond anvil cell: Effect on the volume-based pressure calibration. Geophys. Res. Lett. 20, 1147-1150.

O'Neill, C. and Nimmo, F. (2010) The role of episodic overturn in generating the surface geology and heat flow on Enceladus. Nature Geoscience 3, 88-91.

Pruzan, P., Wolanin, E., Gauthier, M., Chervin, J.C., and Canny, B. (1997) Raman scattering and $\mathrm{x}$-ray diffraction of ice in the megabar range. Occurrence of symmetric disordered solid above 62 GPa. J. Phys. Chem. 101, 6230-6233.

Roth, L., Saur, J., Retherford, K.D., Strobel, D.F., Feldman, P.D., McGrath, M.A., and Nimmo, F. (2014) Transient Water Vapor at Europa's Soputh Pole. Science 343, $6167,171-174$.

Ruiz, J. (2001) The stability against freezing of an internal liquid-water ocean in Callisto. Nature 412, 409-411.

Saur, J., Duling, S., Roth, L., Xianzhe, J., Strobel, D.F., Feldman, P.D., Christensen, U.R., Retherforf, K.D., McGrath, M.A., Musacchio, F., Wennmacher, A., Neubauer, F.M., Simon, S., and Hartkorn, O. (2015) The search for a subsurface ocean in Ganymede with Hubble Space Telescope observations of its auroral ovals. JGR-Space Physics, DOI: 10.1002/2014JA020778.

Schenk, P.M., McKinnon, W.B., Gwynn, D. and Moore, J.M. (2001) Flooding of Ganymede's bright, resurfaced terrains by low-viscosity water-ice lavas. Nature 410, 57-60.

Schubert, G.; Zhang, K.; Kivelson, M.G. and Anderson, J.D. (1996) The magnetic field and internal structure of Ganymede. Nature 384, no. 6609, 544-545.

Shuldiner, A.V. and Zakrevskii, V.A. (2002) The mechanism of interaction of dislocations with point defects in ionic crystals. Journal of Physics: Condensed Matter 14, 9555-9562. 
608

609

610
Simon, F.E. and Glatzel, G. (1929) Bemerkungen zur Schmelzdruckkurve. Z. Anorg. Allg. Chem. 178, 309-316.

Somayazulu, M., Shu, J., Chang-sheng, Z., Goncharov, A.F., Tschauner, O., Mao, H-K., and Hemley, R.J. (2008) In situ high-pressure x-ray diffraction study of $\mathrm{H}_{2} \mathrm{O}$ ice VII. Journal of Chemical Physics 128, 064510.

Waite Jr., J. H., Combi, M.R., Ip, W-H., Cravens, T.E., McNutt Jr., R.L., Kasprzak, W., Yelle, R., Luhmann, J., Niemann, H., Gell, D., Magee, B., Fletcher, G., Lunine, J., and Tseng, W-L. (2006) Cassini Ion and Neutral Mass Spectrometer: Enceladus Plume Composition and Structure. Science 311, 1419-1422.

Wolanin, E., Pruzan, Ph., Chervin, J.C., Canny, B., Gauthier, M., Häusermann, D., and Hanfland, M. (1997) Equation of state of ice VII up to $106 \mathrm{GPa}$. Physical Review $B$ 56, 5781-5785.

Zimmer, C.; Khurana, K.K. and Kivelson, M.G. (2000) Subsurface oceans on Europa and Callisto; constraints from Galileo magnetometer observations. Icarus 147, 329347. 
622 Figure 1. Diffraction pattern of gold, the pressure indicator, and ice VII formed from a 6231.60 mole percent $\mathrm{KCl}-\mathrm{H}_{2} \mathrm{O}$ aqueous solution at $295 \mathrm{~K}$ and $5.41 \pm 0.29 \mathrm{GPa}$. The Miller

624 indices (hkl) of diffraction peaks for gold and ice VII are in gray and black, respectively. 625 No peaks indicative of a solid $\mathrm{KCl}$ phase were observed in any diffraction pattern at 295 $626 \mathrm{~K}$.

628 Figure 2. The pressure-volume relationship of ice VII formed from a 1.60 mole percent $629 \mathrm{KCl}-\mathrm{H}_{2} \mathrm{O}$ aqueous solution at $295 \mathrm{~K}$. The data were fit with a $3^{\text {rd }}$ order Birch-Murnaghan 630 equation of state and compared to previous data for pure ice VII (Hemley et al., 1987).

632 Figure 3. Diffraction patterns showing peaks for gold (gray labels) and ice VII (bolded, 633 black labels) are stacked in order of increasing temperature. Diffraction lines indicative 634 of the $\mathrm{B} 2$ phase of $\mathrm{KCl}$ (black labels) are first observed at temperatures of $400 \mathrm{~K}$ and 635 increase in intensity with increasing pressure. These $\mathrm{KCl} \mathrm{B} 2$ peaks disappear entirely at $636475 \mathrm{~K}$ and $4.34 \mathrm{GPa}$ as the ice began to melt and, presumably, the $\mathrm{KCl}$ dissolved into the 637 high-temperature fluid $\mathrm{H}_{2} \mathrm{O}$. The ice peaks at these conditions sharpen considerably and 638 the ice melts completely during the exposure as a subsequent diffraction pattern has no 639 discernable ice peaks. These patterns suggest melting occurred between $450 \mathrm{~K}$ (4.21 $640 \mathrm{GPa})$ and $475 \mathrm{~K}(4.34 \mathrm{GPa})$; hence, the melting point was estimated as the midpoint of $641463 \pm 0.12 \mathrm{~K}$ and $4.28 \pm 0.07 \mathrm{GPa}$. 
643 Figure 4. The volume of ice as a function of pressure at high-temperatures is plotted

644 relative to the calculated volume at the same pressure and $295 \mathrm{~K}$. The isotherms were

645 calculated using procedures outlined in the text. Whereas all high-temperature data were

646 used to calculate a PVT equation of state, for the sake of clarity, only data collected at

647 increments of $50 \mathrm{~K}$ are displayed in the figure.

648

649 Figure 5. The melting curve of ice VII formed from a 1.60 mole percent $\mathrm{KCl}-\mathrm{H}_{2} \mathrm{O}$

650 aqueous solution is plotted as a function of pressure. The ice VII, ice VII $+\mathrm{KCl}$, and

651 fluid phase fields represent the phase(s) observed by using in situ X-ray diffraction at any

652 given pressure and temperature. Melting curves for pure ice VII (Lin et al., 2004) and ice

653 VII formed from a 1.6 mole percent $\mathrm{NaCl}-\mathrm{H}_{2} \mathrm{O}$ solution (Frank et al., 2008) are presented 654 for comparison.

656 Figure 6. The density of ice VII formed from pure $\mathrm{H}_{2} \mathrm{O}$ (Hemley et al., 1987; Frank et al., 657 2012) is compared to ice VII formed from 1.60 mole percent aqueous solutions of KCl$658 \mathrm{H}_{2} \mathrm{O}$ (this study) and $\mathrm{NaCl}-\mathrm{H}_{2} \mathrm{O}$ (Frank et al., 2012) at $295 \mathrm{~K}$ and as a function of 659 pressure. Ice VII with $\mathrm{K}^{+}$and $\mathrm{Cl}^{-}$ionic impurities was found to be approximately $7 \%$ and $6605 \%$ denser than pure ice VII (Hemley et al., 1987) at 2 and $40 \mathrm{GPa}$, respectively.

661

662 Figure 7 a.) A schematic diagram of a hypothetical extra-solar $\mathrm{H}_{2} \mathrm{O}$-rich planet. b.) The 663 formation of ice VII from a solute-rich fluid will produce a denser phase of ice that may

664 sink below the less dense pure ice VII. As the impurity-laden ice moves to deeper

665 portions of the planet, a portion of the $\mathrm{K}^{+}$and $\mathrm{Cl}^{-}$will exsolve forming solid $\mathrm{KCl}$. The 
666 impurities also depress the melting curve of ice VII and would result in the production of

667 a KCl-bearing $\mathrm{H}_{2} \mathrm{O}$-rich fluid that could then rise back to the subsurface ocean. c.) The

668 proposed pressure-temperature path for this hypothetical extra-solar planet starts in the

669 ice Ih phase field before passing through the fluid $\mathrm{H}_{2} \mathrm{O}$ field and crossing into the

670 stability field of ice VII (diagram modified from one courtesy of Stephen A. Gramsch,

671 Carnegie Institution of Washington).

672 
Frank et al., Potassium-Bearing Ice VII and Ice Planet Dynamics

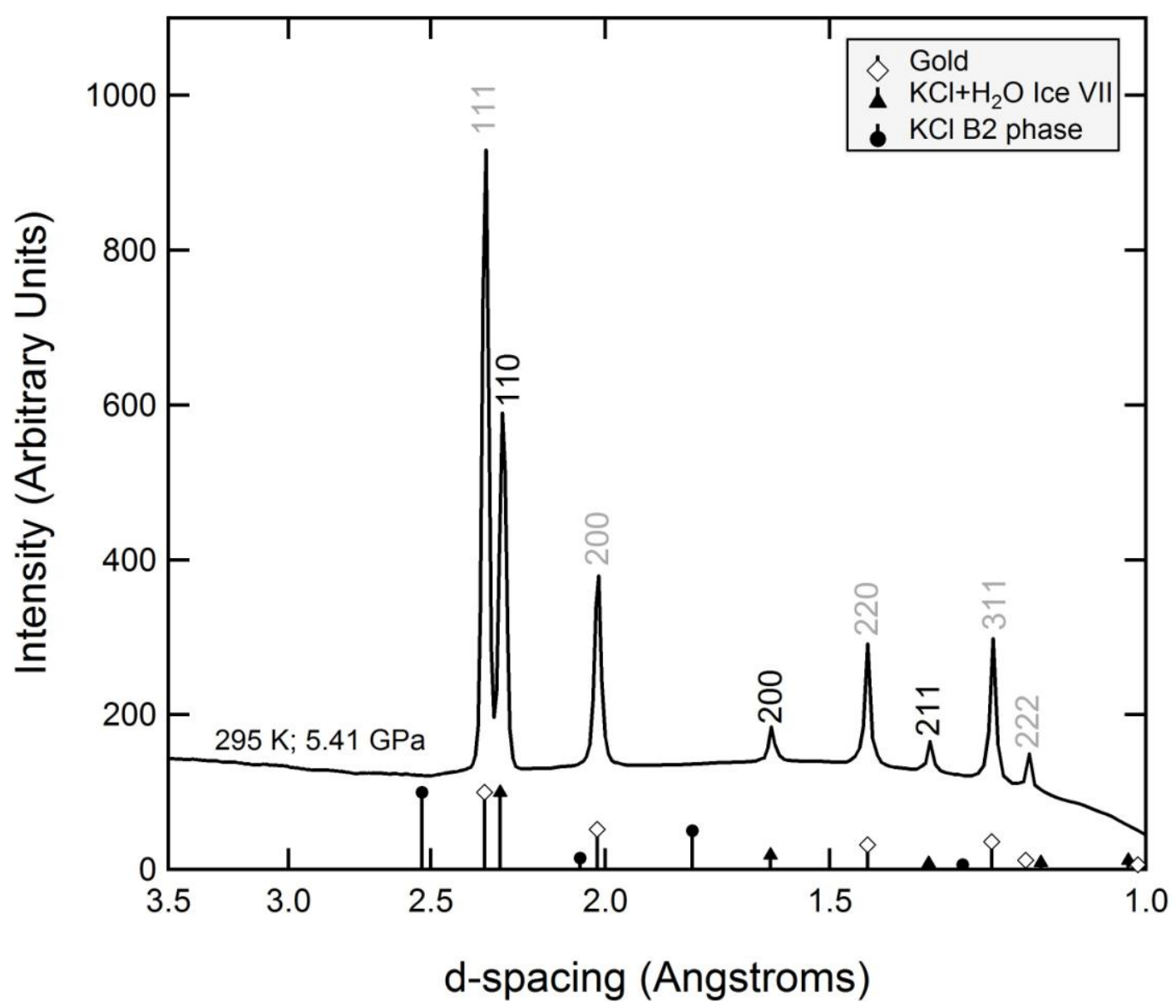

674 Figure 1 


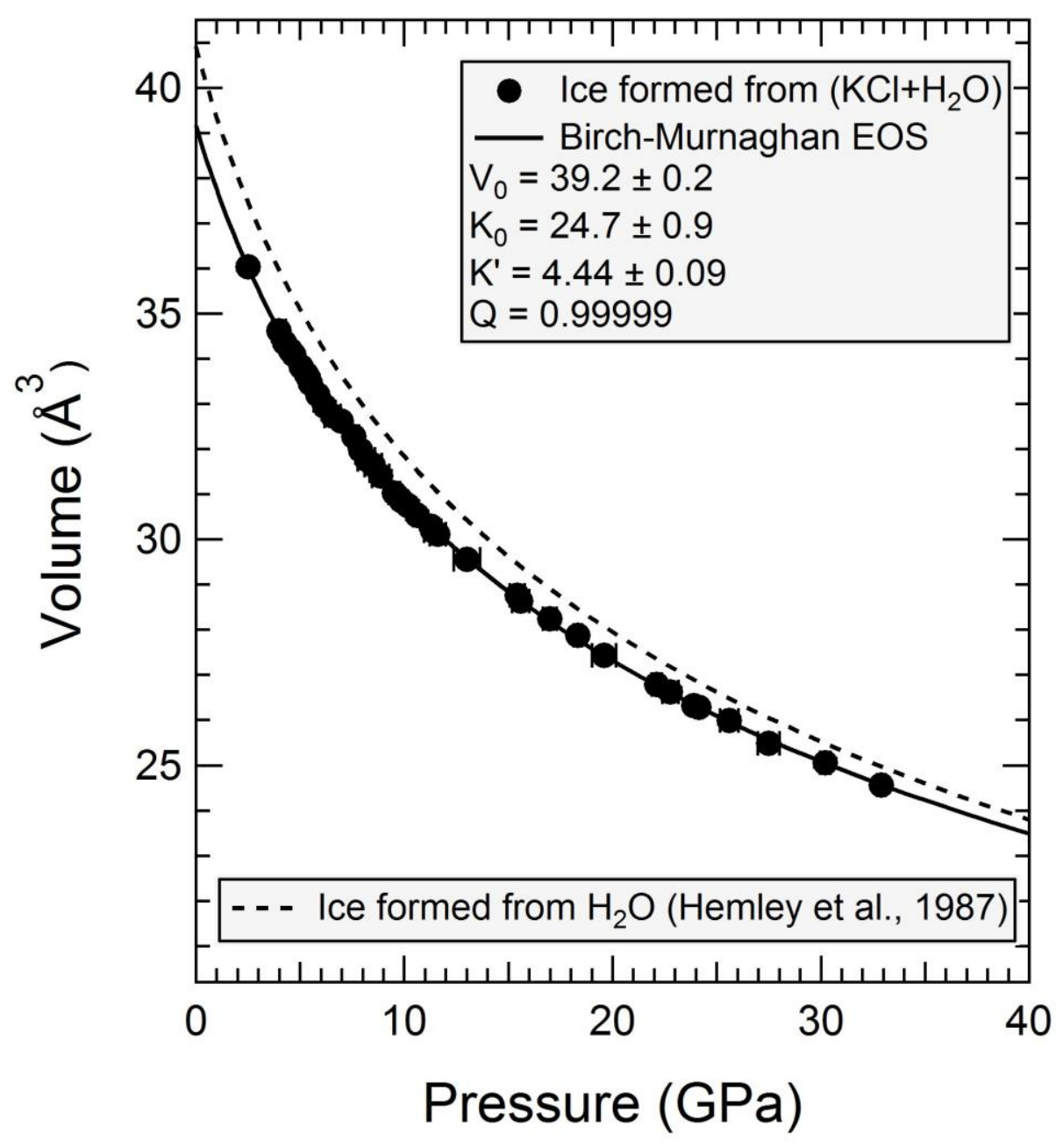

675

Figure 2 
Frank et al., Potassium-Bearing Ice VII and Ice Planet Dynamics

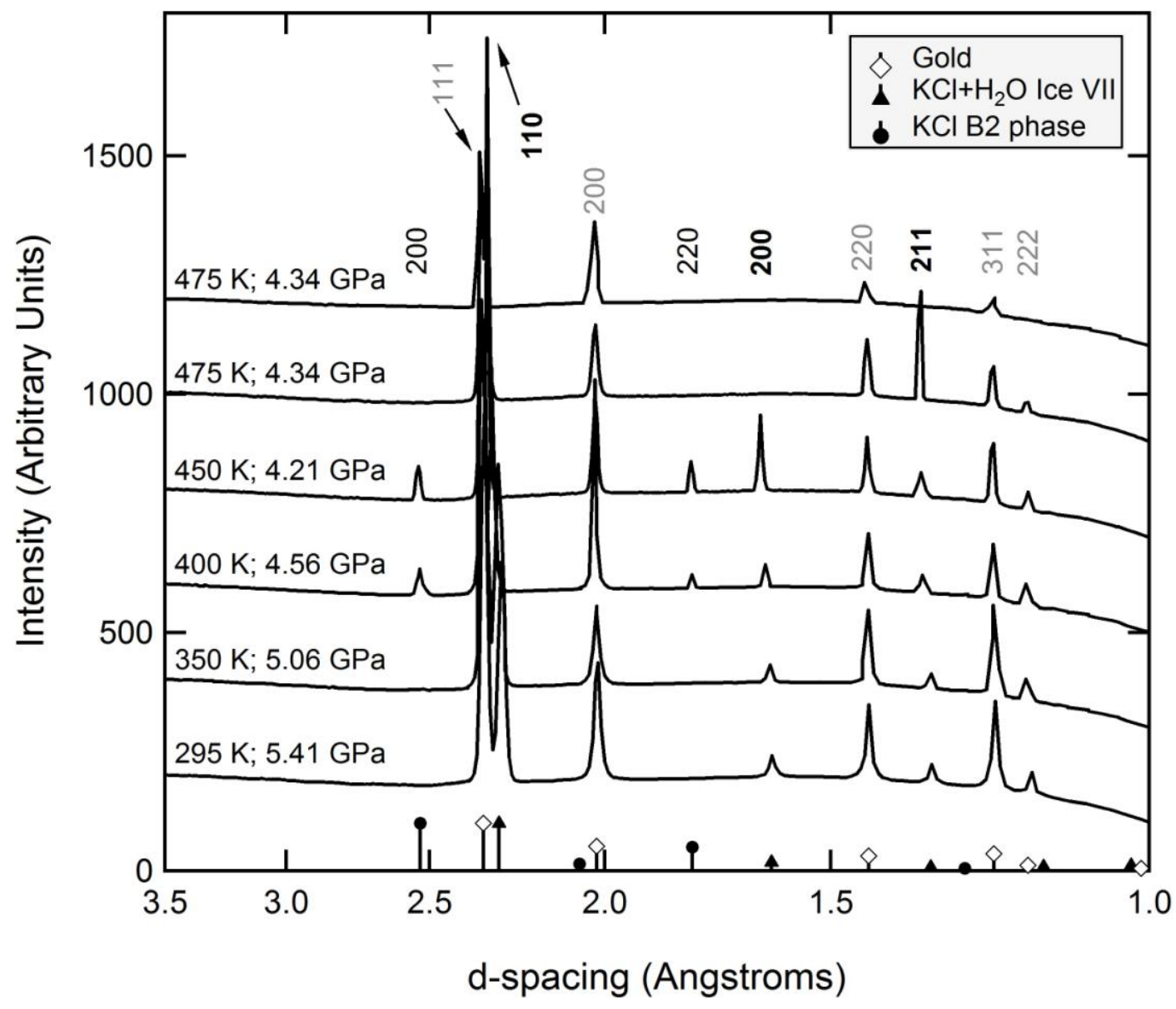

678 Figure 3 
Frank et al., Potassium-Bearing Ice VII and Ice Planet Dynamics

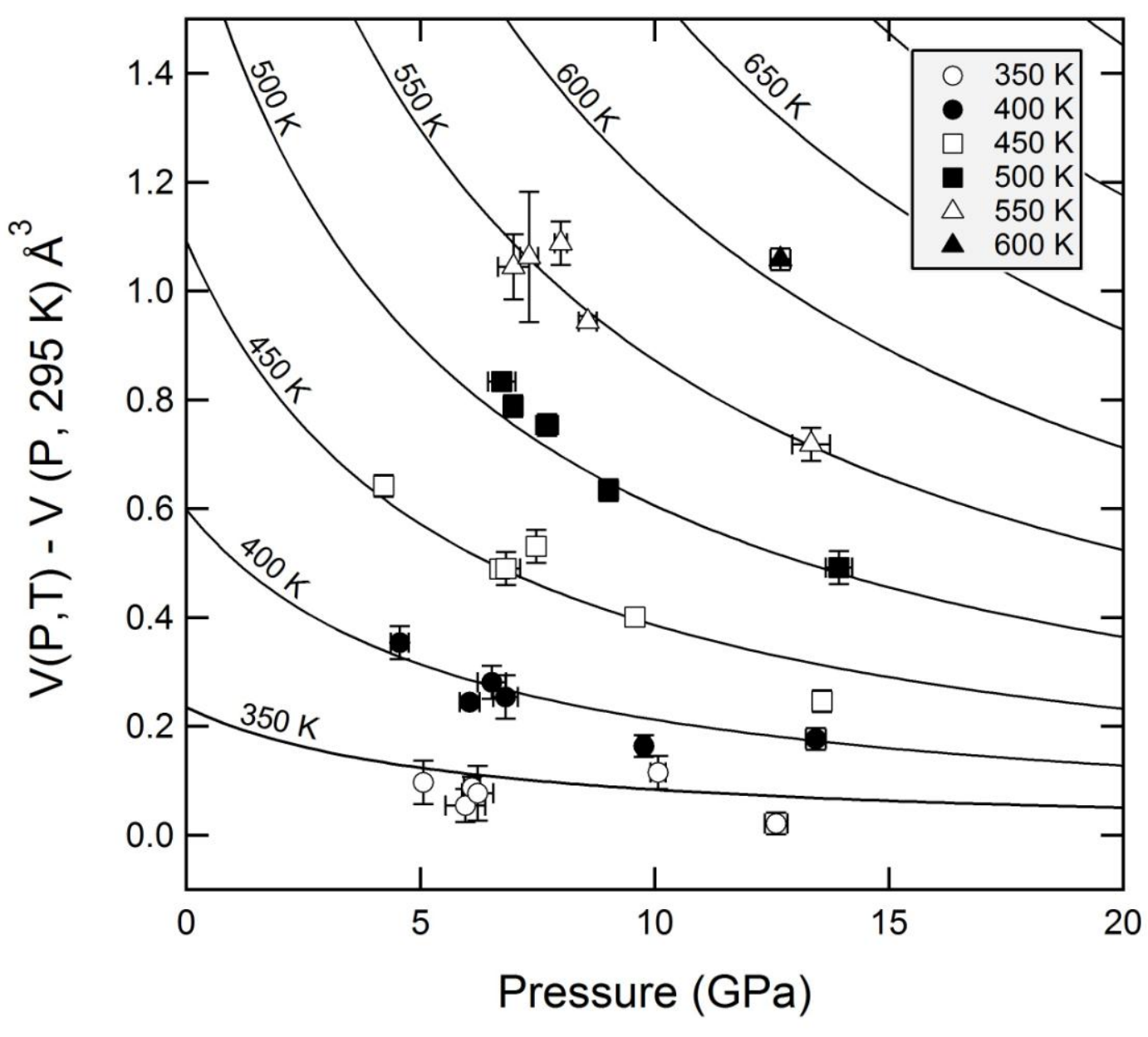

$680 \quad$ Figure 4 


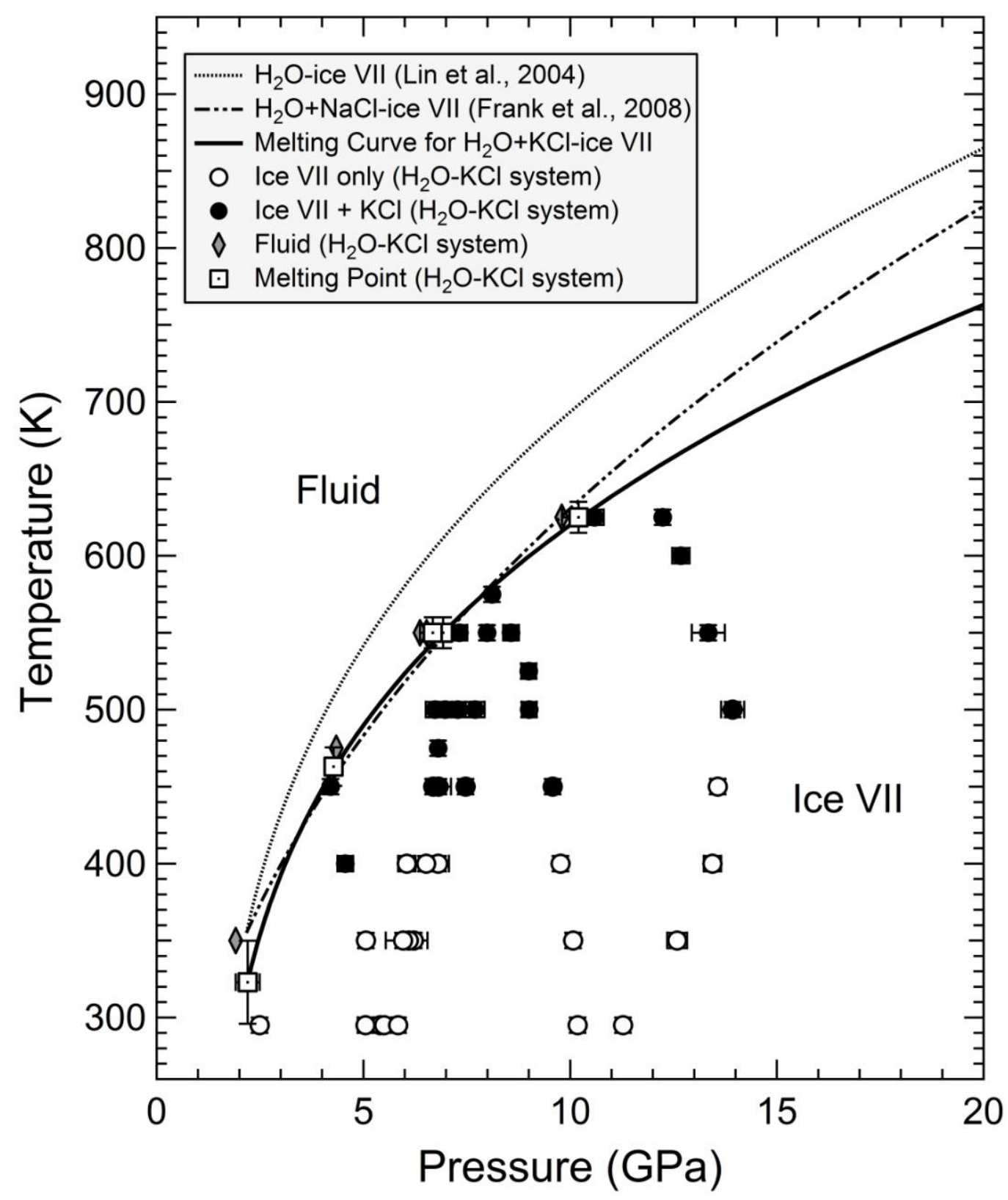

681

682 Figure 5 


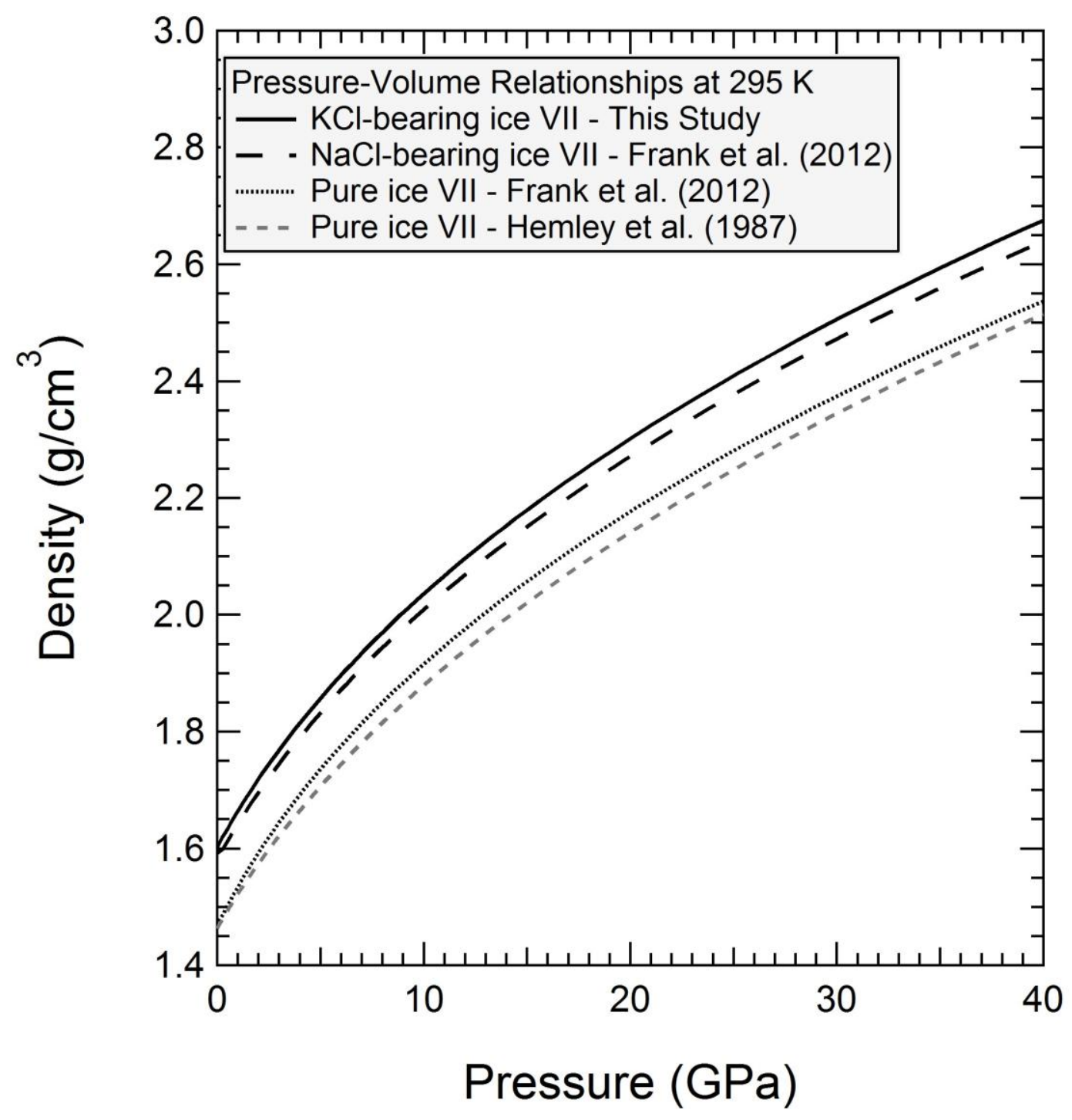

684 Figure 6 
Frank et al., Potassium-Bearing Ice VII and Ice Planet Dynamics

a)

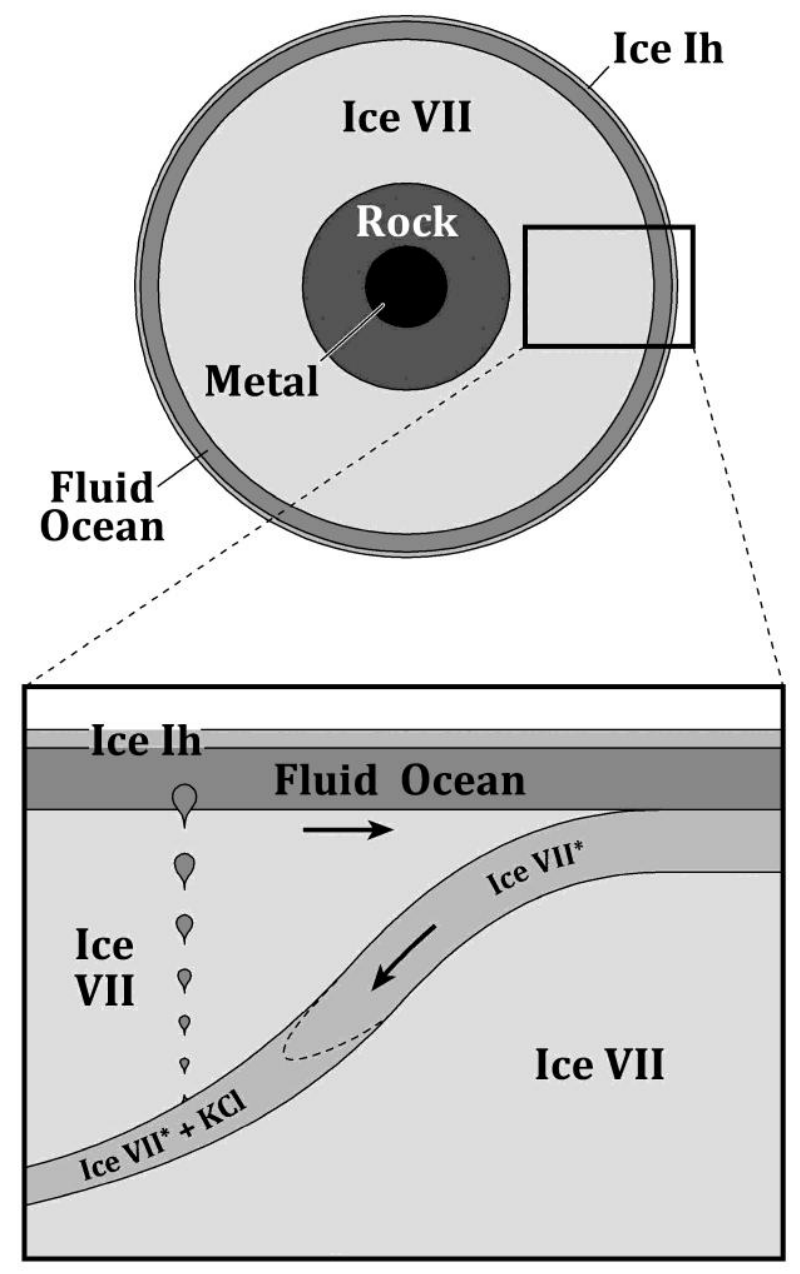

b)

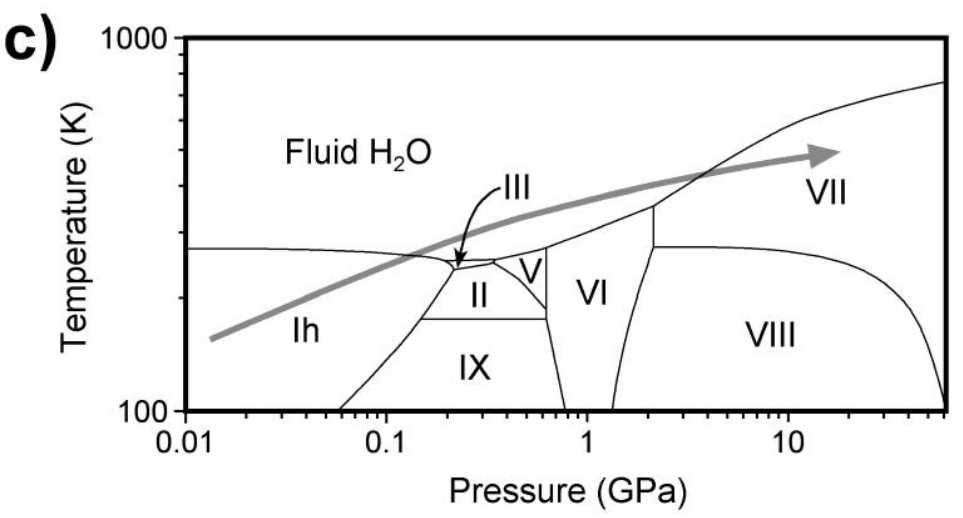

685

Figure 7 
Frank et al., Potassium-Bearing Ice VII and Ice Planet Dynamics

\begin{tabular}{|c|c|c|c|c|c|c|}
\hline $\begin{array}{c}\text { Temperature } \\
(\mathrm{K})\end{array}$ & $\begin{array}{c}\text { Pressure } \\
(\mathrm{GPa})\end{array}$ & $\begin{array}{c}\text { Volume } \\
\left(\AA^{3}\right)\end{array}$ & $\begin{array}{c}\text { Temperature } \\
(\mathrm{K})\end{array}$ & $\begin{array}{c}\text { Pressure } \\
(\mathrm{GPa})\end{array}$ & $\begin{array}{c}\text { Volume } \\
\left(\AA^{3}\right)\end{array}$ & Notes \\
\hline 295 & $2.49 \pm 0.04$ & $36.03 \pm 0.08$ & 350 & " $1.91 \pm 0.07$ & & Fluid \\
\hline 295 & $3.97 \pm 0.34$ & $34.62 \pm 0.06$ & 350 & $5.06 \pm 0.05$ & $33.89 \pm 0.04$ & \\
\hline 295 & $4.25 \pm 0.22$ & $34.35 \pm 0.05$ & 400 & $4.56 \pm 0.19$ & $34.53 \pm 0.03$ & $\mathrm{KCl}$ \\
\hline 295 & $4.54 \pm 0.19$ & $34.19 \pm 0.02$ & 450 & $4.21 \pm 0.07$ & $35.10 \pm 0.02$ & $\mathrm{KCl}$ \\
\hline 295 & $4.70 \pm 0.13$ & $34.09 \pm 0.01$ & 475 & $4.34 \pm 0.13$ & $35.11 \pm 0.04$ & Melting \\
\hline 295 & $5.05 \pm 0.19$ & $33.82 \pm 0.01$ & 500 & $3.66 \pm 0.05$ & NA & Fluid \\
\hline 295 & $5.29 \pm 0.15$ & $33.66 \pm 0.05$ & 350 & $5.96 \pm 0.42$ & $33.21 \pm 0.03$ & \\
\hline 295 & $5.41 \pm 0.29$ & $33.57 \pm 0.03$ & 400 & $6.05 \pm 0.21$ & $33.34 \pm 0.01$ & \\
\hline 295 & $5.50 \pm 0.20$ & $33.46 \pm 0.01$ & 450 & $6.69 \pm 0.09$ & $33.17 \pm 0.01$ & $\mathrm{KCl}$ \\
\hline 295 & $5.84 \pm 0.14$ & $33.20 \pm 0.01$ & 500 & $6.73 \pm 0.29$ & $33.49 \pm 0.01$ & $\mathrm{KCl}$ \\
\hline 295 & $6.17 \pm 0.12$ & $32.95 \pm 0.12$ & 550 & $6.99 \pm 0.33$ & $33.54 \pm 0.06$ & $\mathrm{KCl}$ \\
\hline 295 & $6.57 \pm 0.38$ & $32.73 \pm 0.09$ & 550 & $6.37 \pm 0.33$ & $\mathrm{NA}$ & Fluid \\
\hline 295 & $6.97 \pm 0.15$ & $32.62 \pm 0.05$ & 350 & $6.10 \pm 0.17$ & $33.15 \pm 0.02$ & \\
\hline 295 & $7.57 \pm 0.26$ & $32.28 \pm 0.01$ & 400 & $6.52 \pm 0.30$ & $33.07 \pm 0.03$ & \\
\hline 295 & $7.89 \pm 0.02$ & $31.97 \pm 0.01$ & 450 & $6.82 \pm 0.30$ & $33.09 \pm 0.03$ & $\mathrm{KCl}$ \\
\hline 295 & $8.17 \pm 0.40$ & $31.77 \pm 0.09$ & 475 & $6.81 \pm 0.13$ & $33.29 \pm 0.01$ & $\mathrm{KCl}$ \\
\hline 295 & $8.50 \pm 0.40$ & $31.65 \pm 0.04$ & 500 & $6.98 \pm 0.16$ & $33.29 \pm 0.02$ & $\mathrm{KCl}$ \\
\hline 295 & $8.85 \pm 0.41$ & $31.41 \pm 0.13$ & 500 & $7.28 \pm 0.31$ & $33.08 \pm 0.01$ & \\
\hline 295 & $9.51 \pm 0.28$ & $31.03 \pm 0.04$ & 350 & $10.07 \pm 0.16$ & $30.91 \pm 0.03$ & \\
\hline 295 & $9.79 \pm 0.23$ & $30.90 \pm 0.10$ & 400 & $9.77 \pm 0.12$ & $31.15 \pm 0.02$ & \\
\hline 295 & $9.85 \pm 0.16$ & $30.86 \pm 0.08$ & 450 & $9.58 \pm 0.10$ & $31.48 \pm 0.01$ & $\mathrm{KCl}$ \\
\hline 295 & $10.18 \pm 0.09$ & $30.75 \pm 0.11$ & 500 & $9.01 \pm 0.18$ & $32.00 \pm 0.02$ & $\mathrm{KCl}$ \\
\hline 295 & $10.63 \pm 0.18$ & $30.53 \pm 0.10$ & 525 & $9.00 \pm 0.18$ & $32.10 \pm 0.02$ & $\mathrm{KCl}$ \\
\hline 295 & $11.28 \pm 0.10$ & $30.29 \pm 0.01$ & 550 & $8.57 \pm 0.19$ & $32.54 \pm 0.01$ & $\mathrm{KCl}$ \\
\hline 295 & $11.36 \pm 0.40$ & $30.19 \pm 0.03$ & 550 & $7.32 \pm 0.19$ & $33.36 \pm 0.12$ & $\mathrm{KCl}$ \\
\hline 295 & $11.61 \pm 0.39$ & $30.12 \pm 0.06$ & 550 & $6.53 \pm 0.12$ & NA & Fluid \\
\hline 295 & $13.00 \pm 0.62$ & $29.56 \pm 0.03$ & 350 & $6.22 \pm 0.33$ & $33.06 \pm 0.05$ & \\
\hline 295 & $15.41 \pm 0.37$ & $28.76 \pm 0.08$ & 400 & $6.81 \pm 0.26$ & $32.86 \pm 0.04$ & \\
\hline 295 & $15.59 \pm 0.40$ & $28.64 \pm 0.04$ & 450 & $7.47 \pm 0.05$ & $32.74 \pm 0.03$ & $\mathrm{KCl}$ \\
\hline 295 & $16.97 \pm 0.33$ & $28.24 \pm 0.03$ & 500 & $7.70 \pm 0.23$ & $32.83 \pm 0.02$ & $\mathrm{KCl}$ \\
\hline 295 & $18.34 \pm 0.20$ & $27.88 \pm 0.05$ & 550 & $7.99 \pm 0.13$ & $33.00 \pm 0.04$ & $\mathrm{KCl}$ \\
\hline 295 & $19.60 \pm 0.57$ & $27.44 \pm 0.05$ & 575 & $8.11 \pm 0.13$ & $33.09 \pm 0.03$ & $\mathrm{KCl}$ \\
\hline 295 & $22.11 \pm 0.25$ & $26.79 \pm 0.06$ & 350 & $12.59 \pm 0.24$ & $29.76 \pm 0.02$ & \\
\hline 295 & $22.76 \pm 0.38$ & $26.63 \pm 0.10$ & 400 & $13.44 \pm 0.21$ & $29.58 \pm 0.02$ & \\
\hline 295 & $23.89 \pm 0.15$ & $26.32 \pm 0.06$ & 450 & $13.57 \pm 0.17$ & $29.60 \pm 0.02$ & \\
\hline 295 & $24.15 \pm 0.10$ & $26.28 \pm 0.03$ & 500 & $13.93 \pm 0.28$ & $29.71 \pm 0.03$ & $\mathrm{KCl}$ \\
\hline 295 & $25.60 \pm 0.45$ & $25.99 \pm 0.08$ & 550 & $13.34 \pm 0.40$ & $30.16 \pm 0.03$ & $\mathrm{KCl}$ \\
\hline 295 & $27.49 \pm 0.52$ & $25.49 \pm 0.07$ & 600 & $12.68 \pm 0.21$ & $30.76 \pm 0.02$ & $\mathrm{KCl}$ \\
\hline 295 & $30.21 \pm 0.25$ & $25.06 \pm 0.10$ & 625 & $12.24 \pm 0.12$ & $31.02 \pm 0.03$ & $\mathrm{KCl}$ \\
\hline \multirow[t]{2}{*}{295} & $32.89 \pm 0.19$ & $24.56 \pm 0.04$ & 625 & $10.59 \pm 0.22$ & $31.92 \pm 0.08$ & $\mathrm{KCl}$ \\
\hline & & & 625 & $9.80 \pm 0.05$ & NA & Melting \\
\hline
\end{tabular}


\begin{tabular}{|l|cc|}
\hline \hline & 625 & $6.57 \pm 0.28$ \\
\hline
\end{tabular}

688 standard deviations from the means. Fluid = aqueous $\mathrm{KCl}$-bearing fluid; $\mathrm{KCl}=$ an ice

689 VII and solid phase of $\mathrm{KCl}$ mixture; Melting = a pressure and temperature point at which

690 melting was observed during analysis by X-ray diffraction; NA = not applicable or not

691 observed.

692 


\begin{tabular}{|c|c|c|c|}
\hline \multicolumn{4}{|c|}{ Ice VII Pressure-Volume Fit Parameters at $295 \mathrm{~K}$} \\
\hline & $K_{T 0}(\mathrm{GPa})$ & $K_{T 0}^{\prime}$ & $\mathrm{V}_{0}\left(\AA^{3}\right)$ \\
\hline 1.60 mole $\% \mathrm{KCl}-\mathrm{H}_{2} \mathrm{O}$ (This Study) & $24.7 \pm 0.9$ & $4.44 \pm 0.09$ & $39.2 \pm 0.2$ \\
\hline $\begin{array}{l}1.60 \text { mole } \% \text { NaCl- } \mathrm{H}_{2} \mathrm{O} \text { (Frank et al., } \\
2012 \text { ) }\end{array}$ & $26.47 \pm 0.46$ & $4.27 \pm 0.03$ & $38.96 \pm 0.08$ \\
\hline $\begin{array}{l}1.60 \text { mole } \% \mathrm{CH}_{3} \mathrm{OH}-\mathrm{H}_{2} \mathrm{O} \text { (Frank et al., } \\
2012 \text { ) }\end{array}$ & $21.53 \pm 0.68$ & $4.37 \pm 0.04$ & $41.0 \pm 0.19$ \\
\hline $\begin{array}{l}\text { One-component, } \mathrm{H}_{2} \mathrm{O} \text { (Hemley et al., } \\
\text { 1987) }\end{array}$ & $23.7 \pm 0.9$ & $4.15 \pm 0.07$ & $40.9 \pm 0.9$ \\
\hline One-component, $\mathrm{H}_{2} \mathrm{O}$ (Fei et al., 1993) & $23.9 \pm 0.7$ & $4.2 \pm 0.5$ & $40.9 \pm 0.7$ \\
\hline One-component, $\mathrm{H}_{2} \mathrm{O}$ (Frank et al., 2004) & $21.3 \pm 1.3$ & $4.4 \pm 0.1$ & $41.2 \pm 0.1$ \\
\hline One-component, $\mathrm{H}_{2} \mathrm{O}$ (Frank et al., 2012) & $20.14 \pm 1.11$ & $4.62 \pm 0.07$ & $40.8 \pm 0.33$ \\
\hline $\begin{array}{l}\text { One-component, } \mathrm{H}_{2} \mathrm{O} \text { (Bezacier et al., } \\
\text { 2014) }\end{array}$ & $20.77 \pm 0.26$ & 4 & $41.2 \pm 0.1$ \\
\hline
\end{tabular}

693

694 Table 2. A comparison of the zero-pressure volume $\left(\mathrm{V}_{0}\right)$, bulk modulus $\left(K_{T 0}\right)$, and 695 pressure derivative $\left(K_{T 0}^{\prime}\right)$ of pure ice VII and ice VII formed from 1.60 mole percent 696 aqueous solutions of $\mathrm{KCl}-\mathrm{H}_{2} \mathrm{O}, \mathrm{NaCl}-\mathrm{H}_{2} \mathrm{O}$, and $\mathrm{CH}_{3} \mathrm{OH}-\mathrm{H}_{2} \mathrm{O}$.

697 
698

699

700 Table 3. The pressure-volume-temperature fit parameters for the KCl-bearing ice VII of 701 this study are compared to those of pure ice VII and that formed from a $\mathrm{NaCl}-\mathrm{H}_{2} \mathrm{O}$ 702 solution.

703 


\begin{tabular}{|cc|}
\hline \multicolumn{2}{|c|}{ Ice VII Melting Curve Data } \\
\hline \hline Temperature $(\mathrm{K})$ & Pressure $(\mathrm{GPa})$ \\
$323 \pm 27$ & $2.20 \pm 0.29$ \\
$463 \pm 12$ & $4.28 \pm 0.07$ \\
$550 \pm 5$ & $6.68 \pm 0.31$ \\
$550 \pm 5$ & $6.93 \pm 0.40$ \\
$625 \pm 5$ & $10.2 \pm 0.40$ \\
\hline \multicolumn{2}{|c|}{ Simon fit of Melting Point Data } \\
\hline \hline$c$ & 3.72 \\
$P_{C}$ & 0.759 \\
$T_{t}$ & 324 \\
$P_{t}$ & 2.2 \\
\hline
\end{tabular}

704

705 Table 4. The melting curve of ice VII was determined by using the Simon-Glatzel

706 equation and the melting point data presented here. Some of the data represent midpoints 707 in $P$ - $T$ space between ice-absent and ice-present diffraction patterns whereas others are 708 from experiments where ice was observed to melt in successive patterns.

709 